\title{
Peningkatan Mutu Kompos Kiambang MelaluiAplikasi Teknologi Hayati dan Kotoran Ternak Sapi
}

\section{Improvement of Compost Quality of Kiambang ThroughBiological Technology and Cattle Manure Applications}

\author{
Joko S.S. Hartono, Made Same, dan Yonathan Parapasan \\ Politeknik Negeri Lampung \\ Jln. Soekarno-Hatta No. 10 Rajabasa Bandar Lampung
}

\begin{abstract}
Kiambang (Salvinia natans) which a water plant became a seriously problem in the use of Reservoir Batutegi, because nearly $80 \%$ of its surface covered by Salvinia natans. The presence of highly abundant of Salvinia natans have highly potential to be used as a source of organic fertilizer. The purpose of this study was to examine the effect of the application of biological technology (decomposers) and cow manure on the quality of the resulting compost kiambang. This study used randomized block design and experiment arranged in factorial $4 \times 4$ with three replications. The first factor was the dose of decomposers which consists of 4 levels, namely $A 1=0 \mathrm{ml}, A 2=20 \mathrm{ml}, 30 \mathrm{ml}$ dose $=A 3$, and $A 4=40 \mathrm{ml}$ decomposers per quintal kiambang respectively. The second factor was the dose of cattle dung, i.e. $B 1=0 \mathrm{~kg}, B 2=10 \mathrm{~kg}, 20 \mathrm{~kg}=B 3$, and B4 = $30 \mathrm{~kg}$ manure per quintal kiambang. The results showed the compost that has the best quality in terms of physical and chemical compost was the compost derived from the treatment of $30 \mathrm{ml}$ and $40 \mathrm{ml}$ decomposers per quintal kiambang which combined with $10 \mathrm{~kg}, 20 \mathrm{~kg}$ or $30 \mathrm{~kg}$ manure per quintal kiambang.
\end{abstract}

Keywords: Salvinia natans, decomposers, cow manure, compost quality

Diterima29-07 2014, disetujui: 22-08-2014

\section{PENDAHULUAN}

Kandungan bahan organik tanah pada sebagian besar lahan pertanian di Indonesia telah mencapai aras rendah sampai sangat rendah, sedangkan produktivitas tanah dan keberlanjutan produksi tanaman ditentukan oleh kecukupan kandungan bahan organik tanah. Oleh karena itu, pemberian bahan organik pada tanah pertanian sudah menjadi keharusan. Salah satu bentuk bahan organik adalah kompos, yang merupakan pupuk organik yang berasal dari sisa tanaman dan kotoran hewan yang telah mengalami proses dekomposisi atau pelapukan. Kompos merupakan salah satu komponen untuk meningkatkan kesuburan tanah dengan memperbaiki kerusakan fisik tanah akibat pemakaian pupuk anorganik (kimia) pada tanah secara berlebihan yang berakibat rusaknya struktur tanah dalam jangka waktu lama.

Salah satu bahan baku kompos yang sangat melimpah di Provinsi Lampung adalah gulma kiambang (Salvinia natans) yang keberadaannya telah menutupi hampir $80 \%$ permukaan wakduk 

Batutegi, sehingga menjadi masalah utama dalam pemanfaatan Waduk Batutegi (Balai Besar Wilayah Sungai Mesuji Sekampung. 2012). Dalam waktu satu minggu gulma air ini mampu berkembang dan memperbanyak populasinya menjadi dua kali lipat (Margint, 2012).Kehadiran gulma kiambang yang sangat melimpah tersebut sangat berpotensi digunakan sebagai sumber pupuk organik setelah dikomposkan, sehingga pengomposan gulma kiambang tersebut perlu dilakukan untuk menghindari pengaruh negatif terhadap lingkungan.

Selama ini, pengendalian gulma kiambang di Waduk Batutegi dilakukan dengan mengangkat gulma tersebut, selanjutnya diangkut dengan menggunakan truk tronton dan dibuang di pinggir jalan yang tidak jauh dari waduk. Tumpukan kiambang tersebut dibiarkan mengering dan membusuk, dan belum dimanfaatkan secara khusus untuk tujuan tertentu. Oleh karena itu, dilakukan percobaan pembuatan kompos berbahan baku kiambang yang ditambah dengan kotoran ternak dan dekomposer yang umum beredar di pasaran. Pemanfaataan kompos kiambang dilakukan menekan akibat buruk penggunaan pupuk kimia secara terus menerus dan memperbaiki struktur tanah serta menekan biaya pemupukan pada budidaya pertanian-perkebunan.

Pengomposan adalah dekomposisi dengan menggunakan aktivitas mikroba, kecepatan dekomposisi dan kualitas kompos tergantung pada keadaan dan jenis mikroba yang aktif selama proses pengomposan. Selama proses pengomposan, kondisi optimum bagi aktivitas mikroba perlu mendapat perhatian, misalnya aerasi, kelembaban, media tumbuh dan sumber energi bagi mikroba. Dalam penelitian ini dilakukan pemberian dekomposer sebagai mikroba pengurai dan kotoran sapi sebagai sumber energi serta dekomposer untuk mempercepat dekomposisi bahan organik yang berasal dari gulma kiambang.

Pembuatan kompos secara konvensional umumnya memerlukan waktu yang cukup lama, yakni 4-6 bulan, tetapi dengan menambahkan kotoran ternak dan menggunakan mikroorganisme yang direkayasa, proses tersebut dapat dipercepat, yakni 1-2 bulan (Djuarnani, dkk. 2005). Kotoran ternak yang umum digunakan dalam mempercepat dekomposisi bahan organik adalah kotoran sapi, kerbau, kambing, dan ayam. Berbagai mikroorganisme yang dapat mempercepat proses dekomposisi bahan organik (dekomposer) dari keluarga bakteri, jamur, maupun actinomycetes saat ini sudah dapat dikemas dalam bentuk siap digunakan.

\section{METODE}

Penelitian ini telah dilaksanakan di areal kebun praktek Politeknik Negeri Lampung, selama 2 bulan (Oktober-November 2013). Bahan baku berupa kiambang (S. natans) diambil dari waduk Batutegi, selanjutnya kiambang dipotong dengan ukuran 2-5 cm, dikomposkan sesuai perlakuan penelitian.

Percobaan menggunakan rancangan Kelompok Teracak Lengkap dan perlakuan disusun secara Faktorial 4 x 4 dengan 3 ulangan ( 4 x 4 x 3), sehingga kombinasi faktorial dari perlakuan tersebut menghasilkan $4 \times 4 \times 3=48$ satuan percobaan. Faktor I adalah dosis dekomposer yang terdiri atas 4t taraf yaitu: A1 = $0 \mathrm{ml}, \mathrm{A} 2=20 \mathrm{ml}, \mathrm{A} 3=30 \mathrm{ml}$, dan A4 = $40 \mathrm{ml}$ dekomposer masingmasing tiap kwintal kiambang. Faktor II adalah dosis kotoran sapi yang terdiri atas 4 taraf, yaitu: $\mathrm{B} 1=0 \mathrm{~kg}, \mathrm{~B} 2=10 \mathrm{~kg}, \mathrm{~B} 3=20 \mathrm{~kg}$, dan B4 $=30 \mathrm{~kg}$ kotoran masing-masing tiap kuintal kiambang. Setiap kuiintal campuran kiambang dan kotoran ternak diberi 5 liter larutan dari campuran air dengan dekomposer sesuai dengan perlakuan. Pengamatan terdiri atas: suhu kompos, warna kompos, rasio $\mathrm{C} / \mathrm{N}$, unsur nitrogen $(\mathrm{N}), \mathrm{P}, \mathrm{K}$ dan $\mathrm{Mg}$ kompos yangdiukur pada akhir penelitian. 


\section{HASIL DAN PEMBAHASAN}

\section{Suhu Kompos}

Tabel 1 menunjukkan perubahan suhu selama proses pengomposan, nampak bahwa pada perlakuan A1 (tanpa dekomposer) pada hari ke 28, suhu masih lebih tinggi dari suhu udara, sedangkan pada perlakuan A2 $(20 \mathrm{ml})$, A3 $(30 \mathrm{ml})$ dan A4 $(40 \mathrm{ml})$ dekomposer tiap kuintal kiambang, suhu kompos sudah sama dengan suhu udara saat itu. Hal ini menunjukkan bahwa pada hari ke 28, pengomposan pada perlakuan tanpa dekomposer belum berakhir, sedangkan pada pemberian $20 \mathrm{ml}, 30 \mathrm{ml}$, dan $40 \mathrm{ml}$ dekomposer tiap kuintal kiambang, menunjukkan bahwa pengomposan kiambang telah berlangsung dengan sempurna.

Perlakuan A3 dan A3 mencapai suhu maksimal sejak hari ke-12 sampai dengan ke-16, sedangkan pada perlakuan A1 dan A2 mencapai suhu maksimal pada hari ke-16 sampai hari ke-20 setelah pengomposan. Data di atas mengindikasikan bahwa makin tinggi dosis dekomposer yang diberikan semakin cepat penurunan suhu kompos mendekati suhu udara (suhu kompos pada pemberian $30 \mathrm{ml}$ dan $40 \mathrm{ml}$ decomposer sama dengan suhu udara pada hari ke 22 setelah pengomposan, sedangkan suhu kompos pada pemberian $10 \mathrm{ml}$ dekomposer mencapai suhu udara pada hari ke 26 setelah pengomposan.

Tabel 1. Dinamika suhu bahan selama pengomposan pengamatan hari ke-2 sampai ke-28 pada berbagai dosis dekomposer dan kotoran ternak

\begin{tabular}{|c|c|c|c|c|c|c|c|c|c|c|c|c|c|c|c|}
\hline \multirow{2}{*}{ No. } & \multirow{2}{*}{ Perl. } & \multicolumn{14}{|c|}{ Pengamatan hari ke } \\
\hline & & 2 & 4 & 6 & 8 & 10 & 12 & 14 & 16 & 18 & 20 & 22 & 24 & 26 & 28 \\
\hline 1 & A1B1 & 27,5 & 28,1 & 28,5 & 29,2 & 31,4 & 33,5 & 35,9 & 38,5 & 41,2 & 42,4 & 38,3 & 33,4 & 31,1 & 29,1 \\
\hline 2 & A1B2 & 28,3 & 28,2 & 28,7 & 29,4 & 31,8 & 33,2 & 36,2 & 38,9 & 41,4 & 41,8 & 37,9 & 33,3 & 31,4 & 29,0 \\
\hline 3 & A1B3 & 28,2 & 28,4 & 28,8 & 29,3 & 32,2 & 33,1 & 36,3 & 39,2 & 42,3 & 43,1 & 38,5 & 32,3 & 31,8 & 28,9 \\
\hline 4 & A1B4 & 28,4 & 28,5 & 28,9 & 29,7 & 32,3 & 33,9 & 36,8 & 38,4 & 42,2 & 43,2 & 38,3 & 32,5 & 31,9 & 28,6 \\
\hline 5 & A2B1 & 27,9 & 28,3 & 28,4 & 29,4 & 32,5 & 33,8 & 37,1 & 42,4 & 40,3 & 38,5 & 34,7 & 30,5 & 28,1 & 28,5 \\
\hline 6 & $\mathrm{~A} 2 \mathrm{~B} 2$ & 27,8 & 28,1 & 28,7 & 29,5 & 32,9 & 34,7 & 37,9 & 42,5 & 39,5 & 38,1 & 33,9 & 30,2 & 28,4 & 28,3 \\
\hline 7 & $\mathrm{~A} 2 \mathrm{~B} 3$ & 27,4 & 28,2 & 28,5 & 29,8 & 32,3 & 34,4 & 39,5 & 42,8 & 38,7 & 37,5 & 34,1 & 30,5 & 28,9 & 28,4 \\
\hline 8 & A2B4 & 28,1 & 28,4 & 28,9 & 29,9 & 32,1 & 34,5 & 39,4 & 42,7 & 38,6 & 37,2 & 34,2 & 30,3 & 28,2 & 28,5 \\
\hline 9 & A3B1 & 27,5 & 28,1 & 29,3 & 31,9 & 35,6 & 40,4 & 43,2 & 41,8 & 39,4 & 36,2 & 31,3 & 28,8 & 28,0 & 28,2 \\
\hline 10 & A3B2 & 28,3 & 28,4 & 28,9 & 31,6 & 36,5 & 41,2 & 43,8 & 41,5 & 38,9 & 34,8 & 29,6 & 28,1 & 28,7 & 28,1 \\
\hline 11 & A3B3 & 28,1 & 28,3 & 29,7 & 31,8 & 36,8 & 42,4 & 44,5 & 41,7 & 38,6 & 34,7 & 29,1 & 28,8 & 28,6 & 28,7 \\
\hline 12 & A3B4 & 28,4 & 28,5 & 29,9 & 32,4 & 36,4 & 42,6 & 44,6 & 42,2 & 38,8 & 34,5 & 29,6 & 28,3 & 28,9 & 28,4 \\
\hline 13 & A4B1 & 28,2 & 28,3 & 29,6 & 32,6 & 36,7 & 41,1 & 45,2 & 42,7 & 38,3 & 34,5 & 29,3 & 28,6 & 28,3 & 28,5 \\
\hline 14 & $\mathrm{~A} 4 \mathrm{~B} 2$ & 28,2 & 28,3 & 30,4 & 32,8 & 36,7 & 42,7 & 45,5 & 42,4 & 38,7 & 34,9 & 29,8 & 28,5 & 28,4 & 28,3 \\
\hline 15 & A4B3 & 28,5 & 28,6 & 30,1 & 32,7 & 36,8 & 43,3 & 45,9 & 42,3 & 38,4 & 34,3 & 29,6 & 28,2 & 28,8 & 28,7 \\
\hline 16 & A4B4 & 28,4 & 28,5 & 30,5 & 32,8 & 36,9 & 43,4 & 45,9 & 42,1 & 38,2 & 34,4 & 29,6 & 28,2 & 28,6 & 28,8 \\
\hline
\end{tabular}

\section{Warna kompos}

Pengamatan warna kompos dilakukan pada akhir penelitian dengan hasil seperti tersaji pada Tabel 2. Tabel 2 menunjukkan bahwa pada akhir pengomposan kiambang (hari ke 28), terjadi degradasi warna kompos, yaitu semua perlakuan tanpa dekomposer (A1) berwarna kelabu gelap kehijauan, sedangkan perlakuan20 ml dekomposer (A2) menunjukkan warna yang lebih gelap dari A1, dan perlakuan $30 \mathrm{ml}$ dekomposer (A3) dan $40 \mathrm{ml}$ dekomposertiap kwintal kiambang (A4) menunjukkan warna Hitam. Hal ini lebih mempertegas data suhu bahwa pada perlakuan tanpa dekomposer, kompos belum mencapai tingkat kematangan optimal, sedangkan perlakuan $30 \mathrm{ml}$ dan $40 \mathrm{ml}$ decomposer memperlihatkan bahwa kompos telah mencapai tingkat kematangan optimal. Data tersebut menegaskan bahwa semakin tinggi dosis dekomposer dan kotoran ternak yang diberikan maka pengomposan kiambang semakin dipercepat 
Jurnal Penelitian Pertanian Terapan

Tabel 2. Pengamatan warna kompos pada berbagai dosis dekomposer dan kotoran ternak

\begin{tabular}{|c|c|c|c|}
\hline No. & Perlakuan & $\begin{array}{l}\text { Notasi warna menurut Munsell's soil color } \\
\text { (Standard soil color charts) }\end{array}$ & Jenis warna \\
\hline 1 & A1B1 & $4 / 17,5 \mathrm{GY}$ & Dark greenish gray (kelabu gelap kehijauan) \\
\hline 2 & A1B2 & 3/1 7,5 GY & Dark greenish gray (kelabu gelap kehijauan) \\
\hline 3 & A1B3 & 2/1 7,5 GY & Greenish black (hitam kehijauan) \\
\hline 4 & A1B4 & 2/1 7,5 GY & Greenish black (hitam kehijauan) \\
\hline 5 & $\mathrm{~A} 2 \mathrm{~B} 1$ & $4 / 15 \mathrm{GY}$ & Dark olive gray(kelabu pudar kehitaman) \\
\hline 6 & $\mathrm{~A} 2 \mathrm{~B} 2$ & $3 / 15 \mathrm{GY}$ & Dark olive gray(kelabu pudar kehitaman) \\
\hline 7 & $\mathrm{~A} 2 \mathrm{~B} 3$ & 2/1 2,5 GY & Olive black(hitam pudar) \\
\hline 8 & $\mathrm{~A} 2 \mathrm{~B} 4$ & $2 / 12,5 \mathrm{GY}$ & Olive black(hitam pudar) \\
\hline 9 & A3B1 & $2 / 15 \mathrm{GY}$ & Olive black(hitam pudar) \\
\hline 10 & A3B2 & $2 / 12,5 \mathrm{GY}$ & Black (hitam) \\
\hline 11 & A3B3 & $2 / 12,5 \mathrm{GY}$ & Black (hitam) \\
\hline 12 & $\mathrm{~A} 3 \mathrm{~B} 4$ & $2 / 12,5 \mathrm{GY}$ & Black (hitam) \\
\hline 13 & A4B1 & $2 / 12,5 \mathrm{GY}$ & Olive black(hitam pudar) \\
\hline 14 & A4B2 & $2 / 12,5 \mathrm{GY}$ & Black (hitam) \\
\hline 15 & A4B3 & $2 / 12,5 \mathrm{GY}$ & Black (hitam) \\
\hline 16 & A4B4 & $2 / 12,5 \mathrm{GY}$ & Black (hitam) \\
\hline
\end{tabular}

\section{Sifat Kimia Kompos \\ Rasio C/N}

Hasil sidik ragam terhadap Rasio $\mathrm{C} / \mathrm{N}$ menunjukkan bahwa dosis dekomposer dan dosis kotoran ternak berinteraksi secara nyata terhadap rasio C/N (Tabel 3).

Tabel 3. Nilai rasio C/N kompos pada berbagai dosis dekomposer dan kotoran ternak

\begin{tabular}{lllll}
\hline Perlakuan & B1 & B2 & B3 & B4 \\
\hline A1 & $23.01^{\mathrm{a}}$ & $21.92^{\mathrm{ab}}$ & $21.17^{\mathrm{ab}}$ & $18.22^{\mathrm{bc}}$ \\
A2 & $18.95^{\mathrm{abc}}$ & $14.74^{\mathrm{cd}}$ & $13.65^{\mathrm{de}}$ & $12.86^{\text {def }}$ \\
A3 & $10.34^{\mathrm{defg}}$ & $10.34^{\mathrm{efg}}$ & $9.38^{\mathrm{fg}}$ & $8.91^{\mathrm{fg}}$ \\
A4 & $9.58^{\mathrm{efg}}$ & $8.26^{\mathrm{g}}$ & $8.07^{\mathrm{g}}$ & $7.96^{\mathrm{g}}$ \\
\hline
\end{tabular}

Keterangan: Angka dengan huruf yang berbeda pada kolom yang samamenunjukkan perbedaan nyata berdasarkan uji Tukey pada taraf $5 \%$.

Berdasarkan uji Tukey pada taraf 5\% (Tabel 3), rasio C/N paling rendah adalah perlakuan decomposer A4B2 (40 ml dekomposer dan $10 \mathrm{~kg}$ kotoran ternak), A4B3 (40 ml dekomposer dan 20 $\mathrm{kg}$ kotoran ternak tiap kwintal kiambang), dan A4B4 (40 ml dekomposer dan $30 \mathrm{~kg}$ kotoran ternak tiap kwintal kiambang) dengan kisaran rasio $\mathrm{C} / \mathrm{N}$ 8.26-7.96, yang berbeda tidak nyata dengan A3B1, A3B2, A4B1 A3B3 dan A3B4 dengan kisaran rasio $\mathrm{C} / \mathrm{N}$ adalah 8.91-10.34. Hal ini terjadi karena ada sinergisme antara dekomposer yang memiliki jumlah organisme perombak bahan organik yang lebih kompleks dengan jumlah kotoran ternak sebagai sumber mikroorganisme dan substrat bagi mikroba pengurai.

Pada perlakuan A1 dengan berbagai dosis kotoran ternak, rasio C/N berkisar antara 18.22 -23.01 yang berbeda tidak nyata dengan A2B1, tetapi berbeda nyata dengan A2B3 dan A2B4. Hal ini menunjukkan bahwa pengomposan kiambang berjalan sangat lambat jika tidak menggunakan dekomposer tambahan atau dosis dekomposer sangat rendah, tetapi walaupun dosis decomposer sangat rendah namun disertai peningkatan dosis kotoran ternak maka pengomposan juga akan berlangsung lebih baik. 
Joko S.S. Hartono, Made Same, dan Yonathan Parapasan: Peningkatan Mutu Kompos Kiambang ....

Pada perlakuan A3 dan A4 untuk semua dosis kotoran ternak, rasio C/N lebih kecil dari 10, yang mengindikasikan bahwa kompos pada semua perlakuan tersebut sudah mencapai kematangan optimal.Pendapat yang sama dikemukakan oleh Notohadiprawiro (1999) bahwa tingkat dekomposisi lanjut suatu kompos adalah nilai rosio $\mathrm{C} / \mathrm{N}$ di bawah 10 .

Proses pengomposan merupakan proses menurunkan rasio $\mathrm{C} / \mathrm{N}$ bahan organik hingga sama dengan $\mathrm{C} / \mathrm{N}$ tanah $(8-12)$. Nilai rasio $\mathrm{C} / \mathrm{N}$ dalam proses pengomposan merupakan faktor penting yangmempengaruhi kinerja mikroorganisme. Kompos dengan rasio $\mathrm{C} / \mathrm{N}$ yang tinggi mengindikasikan bahwa perombakan bahan organik tersebut belum sempurna, sedangkan kompos dengan rasio $\mathrm{C} / \mathrm{N}$ yang rendah menunjukkan pengomposan telah berlangsung secara sempurna. Penggunaan karbon sebagai energi bagi mikroba untuk dekomposisi menyebabkan penurunan $\mathrm{C}$ organik kompos. Bahan organik yang memiliki rasio $\mathrm{C} / \mathrm{N}$ sama dengan tanah memungkinkan bahan tersebut diserap oleh tanaman (Djuarnani, dkk. 2005).

\section{Kadar unsur hara N, P, K, dan Mg}

Hasil sidik ragam terhadap kadar N-total kompos menunjukkan bahwa dosis dekomposer dan dosis kotoran ternak berinteraksi secara nyata terhadap kadar N-total (Tabel 5) dan kadar Kalium kompos (Tabel 6), tetapi berinteraksi secara tidak nyata terhadap kadar fosfor (Tabel 7) dan kadar Mg kompos (Tabel 8).

Tabel 5. Kadar nitrogen total pada berbagai dosis dekomposer dan kotoran ternak

\begin{tabular}{lllll}
\hline & Perlakuan & \multicolumn{1}{c}{ B1 } & \multicolumn{1}{c}{ B2 } & B4 \\
\hline A1 & $1.0310^{\mathrm{f}}$ & $1.0517^{\mathrm{f}}$ & $1.0833^{\mathrm{et}}$ & $1.0833^{\text {def }}$ \\
A2 & $1.1997^{\text {def }}$ & $1.4650^{\text {cdef }}$ & $1.5340^{\text {cde }}$ & $1.5573^{\text {cd }}$ \\
A3 & $1.7410^{\text {bc }}$ & $1.9257^{\text {abc }}$ & $2.0637^{\text {ab }}$ & $2.0893^{\text {ab }}$ \\
A4 & $2.0893^{\text {ab }}$ & $2.2173^{\mathrm{a}}$ & $2.2213^{\mathrm{a}}$ & $2.2043^{\text {ab }}$ \\
\hline
\end{tabular}

Keterangan: Angka dengan huruf yang berbeda pada kolom yang sama menunjukkan perbedaan nyata berdasarkan uji Tukey pada taraf $5 \%$.

Tabel 5 memperlihatkan bahwa dengan meningkatnya dosis dekomposer dan dosis kotoran ternak maka kadar N-total kompos juga meningkat. Kadar $\mathrm{N}$ total tertinggi terdapat pada perlakuan A4B3, dan yang teendah ditemukan pada perlakuan A1B1. Variasi kadar N-total pada berbagai dosis decomposer dan kotoran ternak menunjukkan bahwa semakin tinggi dosis dekomposer dan kotoran ternak maka proses perombakan kiambang juga semakin cepat sehingga semakin banyak jumlah karbon yang dilepaskan ke udara dan menyisakan $\mathrm{N}$ dalam kompos kiambang. Menurut Kuswandi (1993), perombakan bahan organik mengakibatkan terlepasnya karbon dalam bentuk $\mathrm{CO}_{2}$ ke udara. Semakin cepat pelepasan $\mathrm{CO}_{2}$ ke udara, maka massa C-organik kompos semakin brkurang, sehingga kadar $\mathrm{N}$ total dapat meningkat, jika aerasi kompos terkendali.

Tabel 6. Kadar kalium pada berbagai dosis dekomposer dan kotoran ternak

\begin{tabular}{lllll}
\hline \multicolumn{1}{c}{ Perlakuan } & \multicolumn{1}{c}{ B1 } & \multicolumn{1}{c}{ B2 } & \multicolumn{1}{c}{ B3 } & \multicolumn{1}{c}{ B4 } \\
\hline A1 & $0.172^{\mathrm{h}}$ & $0.198667^{\text {gh }}$ & $0.229333^{\text {fgh }}$ & $0.228333^{\text {fgh }}$ \\
A2 & $0.249333^{\text {fg }}$ & $0.271^{\text {ef }}$ & $0.270667^{\text {e }}$ & $0.276667^{\text {ef }}$ \\
A3 & $0.326333^{\text {de }}$ & $0.396^{\text {abc }}$ & $0.440333^{\text {ab }}$ & $0.443667^{\text {ab }}$ \\
A4 & $0.351667^{\text {cd }}$ & $0.377667^{\text {bcd }}$ & $0.411667^{\text {abc }}$ & $0.450667^{\text {a }}$ \\
\hline
\end{tabular}

Keterangan: Angka dengan huruf yang berbeda pada kolom yang sama menunjukkan perbedaan nyata berdasarkan uji Tukey pada taraf 5\%. 
Tabel 6 menunjukkan bahwa kadar kalium lebih rendah pada perlakuan dosis dekomposer yang lebih rendah (A1 dan A2), tetapi pada perlakuan dosis dekomposer yang lebih tinggi (A3 dan A4) nampak bahwa kadar K juga lebih tinggi khususnya pada perlakuan B2, B3 dan B4. Kenyataan di atas menunjukkan bahwa jumlah dan aktivitas mikrob menjadi lebih tinggi dengan meningkatnya dosis dekomposer dan dosis kotoran ternak sapi.

Peningkatan dosis dekomposer dan dosis kotoran ternak menciptakan kondisi yang sangat cocok bagi percepatan perombakan bahan organik yang dikomposkan, karena jumlah dan jenis mikrob pengurai yang tinggi disertai dengan ketersediaan substrat yang tinggi dari kotoran ternak akan semakin mempercepat peningkatan populasi dan aktivitas mikrob pengurai sehingga pengomposan akan berlangsung secara cepat, seperti yang terjadi pada perlakuan $30 \mathrm{ml}$ dan $40 \mathrm{ml}$ dekomposer tiap kwintal kiambang yang berkombinasi dengan $20 \mathrm{~kg}$ dan $30 \mathrm{~kg}$ kotoran ternak sapi.

Peningkatan dosis dekomposer dan dosis kotoran ternak tidak berpengaruh secara signifan terhadap kadar fosfor (Tabel 6) dan kadar Mg kompos kiambang (Tabel 7).

Tabel 7. Kadar fosfor pada berbagai dosis dekomposer dan kotoran ternak

\begin{tabular}{lllll}
\hline Perlakuan & B1 & B2 & B3 & B4 \\
\hline A1 & $3.869^{\mathrm{a}}$ & $4.593^{\mathrm{a}}$ & $5.01^{\mathrm{a}}$ & $5.027^{\mathrm{a}}$ \\
A2 & $4.12^{\mathrm{a}}$ & $4.244^{\mathrm{a}}$ & $4.374333^{\mathrm{a}}$ & $4.560333^{\mathrm{a}}$ \\
A3 & $4.027667^{\mathrm{a}}$ & $4.374333^{\mathrm{a}}$ & $4.938333^{\mathrm{a}}$ & $6.488333^{\mathrm{a}}$ \\
A4 & $4.174^{\mathrm{a}}$ & $4.901333^{\mathrm{a}}$ & $5.032667^{\mathrm{a}}$ & $4.742333^{\mathrm{a}}$ \\
\hline
\end{tabular}

Keterangan: Angka dengan huruf yang berbeda pada kolom yang samamenunjukkan perbedaan nyata berdasarkan uji Tukey pada taraf $5 \%$.

Tabel 8. Kadar Magnesium pada berbagai dosis dekomposer dan kotoran ternak

\begin{tabular}{lllll}
\hline Perlakuan & B1 & B2 & B3 & B4 \\
\hline A1 & $0.0437^{\text {a }}$ & $0.0697^{\text {a }}$ & $0.0650^{a}$ & $0.0697^{\mathrm{a}}$ \\
A2 & $0.0760^{\text {a }}$ & $0.0693^{\mathrm{a}}$ & $0.0727^{\mathrm{a}}$ & $0.0770^{\mathrm{a}}$ \\
A3 & $0.0713^{\mathrm{a}}$ & $0.0803^{\mathrm{a}}$ & $0.0777^{\mathrm{a}}$ & $0.0800^{\mathrm{a}}$ \\
A4 & $0.0730^{\mathrm{a}}$ & $0.0757^{\mathrm{a}}$ & $0.0787^{\mathrm{a}}$ & $0.0747^{\mathrm{a}}$ \\
\hline
\end{tabular}

Keterangan: Angka dengan huruf yang berbeda pada kolom yang sama menunjukkan perbedaan nyata berdasarkan uji Tukey pada taraf 5\%.

Tabel 7 dan Tabel 8 memperlihatkan bahwa peningkatan dosis dekomposer dan dosis kotoran ternak berpengaruh tidak nyata terhadap kadar $\mathrm{K}$ dan $\mathrm{Mg}$ kompos. Hal ini diduga terjadi karena kadar $\mathrm{P}$ dan $\mathrm{Mg}$ dalam bahan kompos dan kotoran ternak tergolong sangat rendah sehingga memberikan hasil yang tidak berbeda nyata.

\section{KESIMPULAN}

Kompos yang berkualitas baik adalah yang sudahcukup mengalami pelapukan, yang dicirikan oleh warna hitam, tidak berbau, kadarair rendah dan suhunya sudah sama dengan suhu udara. Pemberian dekomposer dan kotoran ternak dapat meningkatkan kadar N-total dan kalium kompos, tetapi tidak berpengaruh terhadap kadar $\mathrm{P}$ dan $\mathrm{Mg}$ kompos. Kompos yang memiliki kualitas terbaik ditinjau dari segi fisik dan kimia adalah kompos yang dihasilkan dari perlakuan 30 
Joko S.S. Hartono, Made Same, dan Yonathan Parapasan: Peningkatan Mutu Kompos Kiambang ....

$\mathrm{ml}$ atau40 $\mathrm{ml}$ dekomposer tiap kwintal kiambang yang dikombinasikan dengan $10 \mathrm{~kg}$ kotoran ternak, $20 \mathrm{~kg}$ kotoran ternak, atau $30 \mathrm{~kg}$ kotoran ternak masing-masing tiap kwintal kiambang.

\section{UCAPAN TERIMAKASIH}

Penulis menyampaikan ucapan terimakasih kepada Ditjen DIKTI melalui Program Hibah Kompetisi (BOPTN) tahun 2013 yang telah mendukung pendanaan penelitian ini.

\section{DAFTAR PUSTAKA}

Balai Besar Wilayah Sungai Mesuji Sekampung. 2012. Bendungan Batutegi. Kegiatan O\&P Sumber Daya Air, Direktorat Sumber Daya Air, Kementerian Pekerjaan Umum.

Djuarnani, Nan., Kristian., Setiawan, Budi Susilo. 2005. Cara Cepat Membuat Kompos. Agromedia Pustaka, Depok. 74 Hal.

Kuswandi. 1993. Pengapuran Tanah Pertanian. Kanisius. Yogyakarta. 92p.

Margint, Frans. 2012. Gulma Salvinia molesta. http://fransmargint.blogspot.com/ 2012/01/gulmasalvinia-molesta.html. 18 Oktober 2012

Notohadiprawiro, T. 1999. Tanah dan Lingkungan. Direktorat Jenderal Pendidikan Tinggi. Jakarta. $232 \mathrm{p}$. 